\title{
HOLISMO NOS MODELOS TEÓRICOS DE ENFERMAGEM
}

\author{
HOLISM IN THEORETICAL NURSING MODELS \\ HOLISMO EN LOS MODELOS TEÓRICOS DE ENFERMERIAA
}

\author{
David Lopes Neto ${ }^{\dagger}$ \\ Maria Miriam Lima da Nóbrega ${ }^{2}$
}

\begin{abstract}
RESUMO: Neste estudo bibliográfico analitico apresentamos a classificação de nove modelos teóricos de Enfermagem que abordam o pensamento holistico, segundo as escolas de pensamento das Necessidades Humanas, da Interaçāo e dos Resultados. Com base nas definiçōes de holismo, saúde, cliente e enfermagem analisamos a abordagem holistica apresentada pelos seguintes referenciais teóricos: Teoria Ambientalista de Nightingale, Teoria Interpessoal de Peplau, Teoria Filosófica de Hall, Teoria dos Principios Básicos de Henderson, Teoria do Autocuidado de Orem, Teoria Prescritiva de Wiedenbach, Teoria das Necessidades Humanas Básicas de Horta, Teoria da Adaptação de Roy e Teoria Holistica de Levine.
\end{abstract}

PALAVRAS-CHAVE: Holismo, Teorias de Enfermagem.

\section{INTRODUÇÃO}

Nas duas últimas décadas, o termo holismo vem sendo descrito na literatura de enfermagem como método de definiçăo da questăo saúde e dos individuos que compõem o meio ambiente. Tendo em vista que o advir do terceiro milênio substancia o despertar do pensamento humano para um novo paradigma, a visăo holistica surge, nesta virada de século, como um holograma que considera o todo e as partes em que o programa do todo se reflete.

No ambiente cósmico que envolve a enfermagem - ciência que busca o sentido da existência humana - há inúmeras teorias que, apesar de divergirem em seus pensamentos, unem-se num único propósito de abordagem humanistica do ser humano e na tentativa de integralização dos diferentes aspectos que proporcionam ao ser humano um padrăo de vida justo e salutar. Assim, a definiçăo deste ascendente paradigma está intimamente relacionada com o holismo.

Pretendemos com este estudo abordar a relaçăo da abordagem holistica em nove modelos teóricos de enfermagem, enfocando principalmente, os quatro componentes essenciais: ser humano-indivíduo, sociedade-ambiente, saúde e enfermagem, obedecendo a uma divisão classificatória destes modelos, de acordo com as distintas escolas de pensamento da enfermagem.

\section{MATERIAL E MÉTODOS}

Trata-se de um estudo bibliográfico analítico, extraído a partir de levantamento em livros e periódicos, utilizados como referência na disciplina Tendência e metodologia de enfermagem no Curso de mestrado em enfermagem na UFPB, que contemplassem a abordagem holistica

1 Enfermeiro, mestrando em Enfermagem em Saúde Pública. CCS/UFPB

2 Professora do Curso de Mestrado de Enfermagem em Saúde Pública. CCS/UFPB 
na literatura de enfermagem. Procuramos seguir as seguintes etapas do procedimento metodológico: leitura seletiva do material coletado de acordo com os objetivos propostos, fichamento em resumo critico-analitico dos textos selecionados para posterior leitura interpretativa dos conteúdos dos diferentes autores pesquisados e consideraçőes dos pesquisadores sobre o fenômeno evidenciado.

\section{CLASSIFICAÇÃO DAS ESCOLAS DE PENSAMENTO DA ENFERMAGEM}

Partindo do princípio de que as teorias de enfermagem espelham diferentes realidades e de que a enfermagem contemporânea tem ampliado sua atuação para um sentido multidimensional e acoplador da produção artística requerida pela profissão, desenvolvemos este estudo sobre a abordagem holistica classificando as teorias de acordo com as escolas de pensamento da enfermagem (Meleis, 1991). A primeira escola, a das NECESSIDADES HUMANAS, conceitua as funções a serem desenvolvidas pelo enfermeiro, de acordo com a hierarquia das necessidades dos seres humanos. Neste estudo, inserem-se nesta linha Horta, Orem, Henderson, Hall e Nightingale. A segunda, a da INTERAÇÃO, focaliza o processo de relação interpessoal entre o enfermeiro e o cliente. De acordo com o nosso estudo, fazem parte deste contexto Peplau e Wiedenbach. A terceira, a dos RESULTADOS, trata do porquê dos cuidados de enfermagem sem ignorar o "o que" $\mathrm{e}$ " como fazer". As teoristas pertencentes a esta escola concluem que os resultados advêm dos cuidados prestados. Neste estudo incluem-se Levine e Roy.

\section{HOLISMO NOS MODELOS TEÓRICOS DE ENFERMAGEM}

Estudos de Sakis e Skoner (1987) afirmam que a abordagem holistica na enfermagem vem, paulatinamente, sendo evidenciada nas três últimas décadas, mas só a partir da década de oitenta é que o termo passou a ser descrito, uma vez que era deduzido de outros termos, tais como: bio-fisico-social, funçăo integralizadora da totalidade do indivíduo. Considerando que o ser humano tem sido contemporaneamente abordado enquanto um ser multidimensional $\mathrm{e}$ inserido no meio ambiente, a enfermagem, enquanto ciência, vem ampliando os conhecimentos sobre a abordagem holistica com a perspectiva de trabalhar integralmente esta natureza multidimensional do ser humano.

No Brasil, Nogueira (1986) escreveu um trabalho de grande repercussăo para a enfermagem, no qual apresenta uma proposta de abordagem holistica para tal ciência, com o desenvolvimento de métodos alternativos para o tratamento e para a manutençăo da saúde, propiciando uma visăo integral do ser humano individual.

Com o intuito de clarificar o entendimento do leitor, achamos por conveniência definir cinco termos, que serăo amplamente utilizados na análise das teorias.

Holismo - É um novo paradigma que leva em consideraçăo o todo (holos) e as partes em que o programa do todo se reflete, evitando a fragmentaçăo e o reducionismo, através da inter e transdisciplinariedade das ciências, das artes, das filosofias e das tradições espirituais.

Segundo Weil (1991), "(...) HOLISTTICO não é nova religiăo nem nova filosofia nem nova ciência nem nova arte nem novo partido politico nem nova forma de pensamento (...) nem novo coquetel espiritualista (...). Holistico é o calor das mãos, dos coraçōes unidos por cima das diferenças (...)"

Saúde numa abordagem Holistica - É a resultante de condições positivas de vida, de uma interação ecológica-social do ser humano, de um viver bem e em paz, onde sejam respeitados os direitos de cidadania de cada ser humano, para que este tenha acesso à moradia, ao lazer, à educação, ao emprego e a outros condicionantes de um padrão de saúde considerável. 
Para Nogueira (1986), "Saúde Holistica deriva do holismo e baseia-se em uma combinação de conhecimentos e de práticas de saúde adotadas no Ocidente e no Oriente, modernas e antigas, mas que procuram abordar o ser humano nas suas dimensões física, mental e espiritual e dentro de uma visăo cósmica ou universal."

Cliente numa abordagem Holística - É um ser participante, junto com o enfermeiro ou com outro profissional de saúde, do processo saúde-doença.

Ambiente numa abordagem Holística - É a natureza planetária. É um processo interativo e de equilibrio entre o ser humano e o ambiente ecológico-planetário no qual este se encontra inserido.

Enfermagem numa abordagem Holistica - A abordagem holistica na enfermagem varia de acordo com os modelos teóricos, tendo em vista que cada teoria apresenta características peculiares e que, universalmente, são trabalhadas independente do modelo teórico. Citamos:

a) Harmonia, equilibio e interação em um todo funcional de todos os aspectos, qualidades e potencialidades do indivíduo e/ou da coletividade;

b) Assistência centrada no individuo e/ou na coletividade, focalizando-o como uma unidade indivisivel e em constante interaçăo com o meio ambiente;

c) Melhoria das condiçőes de saúde do indivíduo e/ou da coletividade de acordo com o seu grau de dependência;

d) Atençăo integral às necessidades humanas básicas do indivíduo e/ou da coletividade, abordando os aspectos bio-psico-sócio-espiritual;

e) Utilizaçăo de tecnologia aplicada à saúde dos seres humanos;

f) Desenvolvimento de métodos naturais que promovam, protejam e recuperem a saúde do individuo e/ou da coletividade.

\section{MODELOS TEÓRICOS DE ENFERMAGEM X ABORDAGEM HOLISTICA}

\section{TEORIA AMBIENTALISTA DE FLORENCE NIGHTINGALE}

A organizaçăo dos serviços de Enfermagem começou em meados do século XIX, sob o comando de Florence Nightingale (1989), tendo suas bases no humanismo e o seu foco central baseado no cuidado de enfermagem ao ser humano em sua inter-relaçăo com o meio ambiente. Vocacionada a cuidar dos doentes e necessitados, os serviços assistenciais nightingalianos abrangiam o ser humano a partir de uma visăo holistica contempladora de diferentes fatores que envolviam, naquela época, os seres humanos - guerra, miséria, desnutrição, fome, condições sanitárias insalubres.

Neste estudo tentamos desvendar a abordagem holistica já abordada no início da enfermagem organizada. Nightingale (1989) mesmo năo citando em seus trabalhos a abordagem holistica, deixou-a explicita na sua abordagem técnico-prática. Holisticamente, Nightingale (1989) voltava a sua atenção ao ser humano numa dimensăo generalizada, onde năo apenas o ser enquanto individuo, mas a humanidade estava em perfeita harmonia e interaçăo com os ambientes social, político e ecológico.

Podemos observar que, no ambiente físico, a abordagem holistica é evidenciada quando săo contemplados os componentes ambientais naturais (o ar, a água, o céu, o sol), pois ela ao considerar que o desequilíbrio de um destes componentes levaria ao surgimento de nosologias, estava considerando a ecologia planetária. Desta forma, podemos inferir que a visão holística do enfermeiro sobre o ambiente físico está no seu conhecimento técnico para a aplicabilidade de suas açōes na promoçăo, na proteçăo e na recuperaçăo do individuo

Ao trabalhar o 
ambiente psicológico, Florence considerou a condiçăo emocional como fator de intervenção ou năo no tratamento dos doentes. Para ela, o paciente necessitava de algo mais do que o ambiente físico. Valorizava, assim, a relaçăo enfermeiro-cliente como meio de dirimir as angústias, os sofrimentos e a solidăo dos enfermos. Com isto, notoriamente a abordagem holistica se evidencia ainda mais pela construçăo do ambiente de ajuda e pelo cuidado totalitário prestado por Florence, incluindo o ambiente espiritual. Abordando o ambiente social, a teorista aproximou-se muito mais da abordagem holistica, uma vez que focalizou o ambiente total do individuo, extrapolando - espaço hospitalar e considerando todo o seu contexto comunitário para a compreensăo do seu estado de saúde-doença.

Sumariamente, a Teoria Ambientalista de Nightingale constitui-se de uma interação entre os ambientes físico, psicológico, social e espiritual, os quais associados a ação do enfermeiro podem levar à identificação de fatores determinantes do processo saúde/doença. Por fim, a essência desta teoria baseia-se num ambiente positivo, limpido, transparente e salutar ao viver de seres humanos que necessitam de ajuda e de cuidados.

\section{TEORIA INTERPESSOAL DE PEPLAU}

Hildegard Peplau considera a enfermagem uma arte terapêutica e um processo interpessoal, onde cada individuo é visto como um ser bio-psico-sócio-espiritual, dotado de crenças, costumes, usos e modos de vida voltados para determinada cultura e ambiente diversificado. Para Peplau (1988), a enfermagem é uma relação humana entre um indivíduo que está doente ou necessitando de serviços de saúde e um enfermeiro preparado para reconhecer às necessidades de ajuda do paciente.

Segundo Belcher e Fish (1993), nesta teoria o enfermeiro desenvolve diferentes papéis durante o processo de relaçōes interpessoais, tais como: compartilhando conhecimentos (educador), auxiliando as pessoas no reconhecimento de seus problemas (conselheiro), exibindo seus conhecimentos teórico-práticos (especialista) e liderando grupos (líder).

O processo de relação interpessoal segue quatro fases seqüenciais que dão um direcionamento ao fato. A primeira, é a de orientação - onde deve existir um reconhecimento mútuo entre enfermeiro e paciente, preservando-se as experiências de vida, a religiăo, a etnia e a cultura de cada ser vivo. Nesta fase, a enfermagem atua holisticamente, pois o enfermeiro interage com seu semelhante, considerando seus valores. A segunda, é a fase da identificaçăo, onde está inclusa a afinidade ou năo do enfermeiro e do paciente, pois para cada situação haverá comportamentos diferentes. Nesta fase, há uma reação e uma seletividade dos cuidados pelo próprio paciente, o que contribui significativamente para o estabelecimento da relação enfermeiro-paciente. A terceira, denominada de fase de exploraçăo, dá ao paciente um certo grau de controle sobre o seu ambiente. O enfermeiro, nesta fase, tem um papel significativo, pois de seu trabalho interativo surgirăo os caminhos a serem percorridos pelo paciente, para a busca da solução, que é a quarta fase. Esta fase é a mais dificil por tratar-se da fase de dissoluçăo da relaçăo terapêutica, onde enfermeiro e paciente têm que seguir seus caminhos. A teoria interpessoal de Peplau extrapola o âmbito do paciente e conquista uma dimensão mais abrangente envolvendo familia e comunidade.

Esta ampla dimensão denota uma macrovisăo, entendida neste estudo como uma visăo holistica, pois o texto de Peplau descreve que devem ser consideradas as visőes tanto do profissional quanto do paciente, para que se possa chegar a uma maior compreensão das dificuldades que envolvem a relação e para que se possam adquirir, com mais facilidade, as devidas soluções. Logo, o processo interativo é um processo holístico, onde todas as verdades são respeitadas e aceitas, assim como os valores, as crenças, as experiências e as expectativas de vida de cada indivíduo. 
Lydia E. Hall ao desenvolver os aspectos filosóficos básicos de enfermagem procurou garantir a qualidade dos cuidados profissionais nesta área. Para apresentar sua teoria, Hall estabeleceu, simbolicamente, a interligaçăo de três círculos, que individualmente referendam um aspecto da enfermagem:

a) O circulo de CUIDADOS - Este representa claramente o envolvimento do enfermeiro com as necessidades humanas básicas do ser humano. Neste círculo, Hall preocupou - se com os aspectos ligados às ciências naturais (o conforto espiritual) e às ciências biológicas (cuidados e auxilio na execução das funçőes inerentes ao ser humano) (George (1993). A teoria objetiva assegurar uma interrelação enfermeiro-paciente, onde se cria um ambiente de "exploração de sentimentos" para que se consolide o processo de ensino-aprendizagem dentro do plano assistencial.

b) O circulo da ESSÊNCIA - Neste circulo, o enfermeiro desenvolve uma relação interpessoal terapêutica com o paciente, visando a motivaçăo do paciente para a auto-identidade na tomadas de decisőes. George (1993), citando Hall, diz que o paciente, a partir dos atos e dos reflexos transmitidos pelo enfermeiro, tem capacidade de descobrir suas dificuldades e seus problemas, o que comprova o enunciado deste círculo.

c) O círculo da CURA - Este está baseado na nosologia, no modo de tratamento e na integralização do enfermeiro com os demais membros da equipe multiprofissional de saúde e com a familia do paciente. O enfermeiro, nesta fase, trabalha mecanicamente suas potencialidades técnicas para a obtenção da cura do paciente. A abordagem holistica se evidencia pela integralidade do enfermeiro com os demais individuos que estăo envolvidos, direta ou indiretamente, no processo de cura do paciente, pela totalidade de açőes a serem desenvolvidas com o objetivo único de recuperar o individuo enfermo.

Assim, a visăo holistica da teoria de Hall está em ver o ser humano num todo, onde a motivaçăo para o desenvolvimento das açōes e a energia positiva são elementos vitais para a manutençăo da vida.

\section{TEORIA DOS PRINCIPIOS BÁSICOS DE ENFERMAGEM DE HENDERSON}

A teoria de Virgínia Henderson insere-se na linha das necessidades humanas básicas, cujo foco principal é o cuidado para como o individuo baseado nos quatorze componentes de cuidados básicos de enfermagem, os quais dão à teoria uma macrovisăo ou visăo totalitária sobre o individuo, ou seja, Henderson utiliza-se da abordagem holistica para estabelecer um plano assistencial globalizado. Para Henderson, citada por Furukawa e Howe (1993), mente e corpo săo inseparáveis, estando estes em pleno interrelacionamento para o desenvolvimento das funçöes do ser humano e que o enfermeiro convive num ambiente de sociedade, relacionando-se constantemente com seu próximo.

Segundo Henderson (1969), o momento básico do cuidado de enfermagem pode ser derivado das necessidades humanas assim como de todos os serviços de saúde prestados ao paciente. Ao atuar sobre as necessidades dos seres humanos a enfermeira tem sido chamada de "mãe profissional", principalmente quando esta se responsabiliza pelos cuidados integrais ao paciente. A visăo holística está bem definida nesta teoria, onde ela cria um ambiente harmonioso e interativo entre profissionais, clientes, pacientes e sociedade.

A autora descreve perfeitamente a abordagem holistica, por considerar o hemisfério direito do ser humano. Ela questionava por que a intuiçăo da experiência vivencial de cada indivíduo năo era enfatizada no processo de enfermagem. Em seus estudos, argumenta que o processo de enfermagem desconsidera e subestima o lado artístico, intuitivo e subjetivo da enfermagem. Analisando seus estudos teóricos, concluimos que a Enfermagem tem-se preocupado apenas 
em desenvolver os componentes do hemisfério cerebral esquerdo: o cientificismo, o individualismo, a competitividade, a racionalidade, o reducionismo, e a visăo fragmentada e que pouco se tem envolvido com a intuiçăo, com os valores e com a totalidade bio-psico-sócioespiritual dos homens.

\section{TEORIA DO AUTOCUIDADO DE OREM}

No inicio de seus estudos sobre o autocuidado Orem (1991) direcionou a essência filosófica da sua teoria apenas ao ser humano num plano individualizado. Após diversos estudos, ampliou sua temática para a inclusão de um contexto coletivo, envolvendo familias, grupos sociais e comunidades e, também, definiçăo dos planos de trabalhos entre o enfermeiro e o cliente. A abordagem holistica é descrita na teoria de Orem, a partir do momento em que esta autora desenvolve uma ampliaçăo do papel da enfermagem enquanto ciência voltada à saúde dos seres humanos, seja no sentido individual, seja no sentido multipessoal. Partindo da definição de que o autocuidado é a "prática de atividades iniciadas e executadas pelos individuos em seu próprio benefício para a manutençăo da vida, da saúde e do bem-estar", ela afirma que todo ser humano é dotado de habilidade e percepçăo de sua estrutura bio-psico-social e que, quando há qualquer interferência no processo harmonioso desta estrutura, acontece o devio da saúde. Diz ainda que o próprio ser humano é capaz de executar açǒes de controle que venham amenizar os desvios que estejam influindo na manutençăo do ciclo vital.

A categorizaçăo da teoria de Orem assume uma vertente holistica quando esta autora perpassa a utilizaçăo do autocuidado no desvio de saúde e inclui as necessidades de autocuidado universais e desenvolvimentais. Nestes dois últimos, a vida năo é vista apenas num sentido singular, mas numa gama de processos ligados entre si, que envolvem os homens em todos seus estágios para a manutenção da saúde. A manutençăo da ingestão de ar, de água e de alimento săo importantes, mas a interaçăo social, os talentos das pessoas, o acesso igualitário aos serviços de saúde săo, também, de igual importância.

Tendo em vista que nem sempre será possivel a realizaçăo do autocuidado, Orem (1991) descreveu, nesta mesma teoria, a Teoria de Déficit do Autocuidado, especificando a necessidade de o enfermeiro ajudar o cliente prestando seus serviços. Ao identificar os métodos de ajuda, ela age holisticamente, dando ao enfermeiro a oportunidade de agir ou fazer algo em beneficio do próximo, de guiar o cliente de acordo com suas necessidades, de apoiá-lo psicologicamente em uma harmoniosa relaçăo enfermeiro-cliente e de proporcionar um ambiente salutar e confortante para a promoçăo do bem-estar pessoal. Orem acredita no potencial dos seres humanos em aprender e desenvolver o autocuidado, definindo seres humanos como seres que "diferem de outras coisas vivas, por sua capacidade de refletir acerca de si mesmos e de seu ambiente." O aspecto humanístico desta teoria é uma abordagem holistica, principalmente pela credibilidade atribuida ao ser humano.

A abordagem holistica se fortalece na teoria de Orem e na definiçăo de enfermagem, a qual é vista como arte desejada e necessária na funçăo prática dos enfermeiros focalizada na globalizaçăo dos seres humanos, onde os papéis do enfermeiro e do cliente se complementam numa conotaçăo de que a verdade totalitária do processo saúde/doença năo está dividido entre as partes.

\section{TEORIA PRESCRITIVA DE WIEDENBACH}

Ernestine Wiedenbach (1958) define enfermagem como sendo uma atividade em que 0 profissional presta ajuda a outrem, realizando suas açőes com compaixăo, habilidade, aconselhamento, sabedoria e confiança. Identifica, em sua teoria, três componentes essenciais para uma filosofia holistica da enfermagem: reverência pelo dom da vida, respeito pela dignidade, 
pelo valor, autonomia e individualidade de cada ser humano e resolutividade para a açăo dinâmica, em relação às crenças de cada individuo. Enfatiza o ser humano como potencialmente sábio e cônscio de suas necessidades assinalando, também, que o processo é fundamentado pelo senso de integralidade e auto-estima do individuo (Bennet, Foster, 1993).

A teorista exemplifica em seus postulados que quando o cuidado de enfermagem em atençăo materna está centrado na familia, a gravidez é acompanhada năo meramente como uma experiência natural e fisiológica, mas como um significante processo social essencial ao crescimento e desenvolvimento harmonioso no seio familiar. A abrangência desta atençăo constróise numa abordagem holistica a partir da inclusão de quatro áreas principais de serviços: promoção da saúde fisica, mental e emocional, promoçăo de bem-estar social e promoçăo da paz espiritual (Wiedenbach, 1958).

Wiedenbach vê a saúde como um estado de completa harmonia dos seguimentos biofísico-mental-social e espiritual. Logo, vê o ser humano, em sua totalidade, inserido num ambiente receptor de influências externas. Com isso, a enfermagem é tida como uma ciência e como uma arte, numa junçăo de desenvolvimento de conhecimentos e de habilidades no sentido de satisfazer as necessidades dos seres humanos. A abordagem altruísta e filosófica configura a essência do pensamento holístico desta teoria, em que Wiedenbach citado por Bennet e Foster (1993), afirma que "A enfermagem [é] uma atividade que, idealmente, exemplifica a humanidade do ser humano para com o ser humano."

\section{TEORIA DAS NECESSIDADES HUMANAS BÁSICAS DE WANDA HORTA}

A Teoria das Necessidades Humanas Básicas de Horta, mesmo tendo surgido no início da década de setenta, só a partir de 1974, com a sua segunda publicaçăo, é que ampliou o seu suporte teórico como base para a sistematizaçăo das açőes de enfermagem. Esta teoria se fundamenta nos pressupostos teóricos de Maslow, através da Teoria da Motivaçăo Humana, da Teoria Homeostásica de McDoWell e da Teoria Holistica de Levine. O modelo teórico de Horta engloba os princípios que regem os fenômenos relacionados com as necessidades humanas e com o meio ambiente e a compreensão do ser humano como um ser composto de partes que compõem o seu todo.

Ao criar a sua teoria Horta (1979), afirma que a assistência ao individuo, à familia ou à comunidade será produzida com o objetivo de torná-lo cada vez mais independente dessa assistência, pelo ensino do autocuidado, da recuperaçăo, da manutençăo ou da promoçăo da saúde, em açōes conjuntas, inclusive com os demais membros que compōem a equipe multiprofissional de saúde. Em seu modelo, emprega o processo de enfermagem nas seguintes fases: histórico de enfermagem, diagnóstico de enfermagem, plano assistencial de enfermagem, prescriçăo de enfermagem, evoluçăo e prognóstico de enfermagem como forma de direcionar as açőes a serem desenvolvidas.

Ao discorrer sobre o ser humano, considerado parte do cosmo em permanente dinamismo, a autora enfatiza esta interrelaçăo como sendo este um processo harmonioso, onde o ser humano está sujeito aos fenômenos que regem o universo. A abordagem holistica torna-se mais esclarecida quando considera, na teoria, que "o universo é um todo, o ser humano é um todo, a célula é um todo; esse todo năo é mera soma das partes constituintes de cada ser." (Horta, 1979)

\section{TEORIA DE ADAPTAÇÃO DE SISTER CALLISTA ROY}

O modelo de Adaptaçăo de Roy é composto de cinco elementos essenciais: a pessoa que recebe o cuidado de enfermagem, a meta da enfermagem, a definição de saúde, a definiçăo de ambiente e as atividades de enfermagem. Roy percebe que a enfermagem é prestadora de 
cuidados tanto a uma pessoa quanto a uma família, a um grupo de pessoas, a uma comunidade ou a uma sociedade. A visualização do enfermeiro, perante estes diferentes atores, é tida como um sistema holistico e adaptativo, onde há uma constante interaçăo destes com seus ambientes. Há, também, a manutenção das integralidades dessas pessoas, o que caracteriza o processo adaptativo. (Galbreath, citado por George, 1993)

A meta da enfermagem é definida como a promoçăo de respostas adaptativas influenciadoras, de modo positivo, no processo saúde/doença. A adaptaçăo da pessoa às mudanças que a afeta, depende de estimulos externos ou internos que estăo em proximidade dessa pessoa. A abordagem holistica, neste processo, está em considerar que o individuo é capaz de adaptar-se aos estimulos que o circunda ou de enfrentá-los positivamente. Logo, Roy atribuia ao seu modelo teórico valores humanísticos que fornecem à pessoa capacidades que Ihe proporcionarăo forças advindas do dinamismo e da criatividade pessoal da pessoa assistida, principalmente em participar, junto com o enfermeiro, do cuidado que este lhe vai prestar (Roy, 1984).

Em 1987, a definição do termo saúde, empregada por Roy, é a seguinte: “(...) um estado e um processo de ser e vir a ser uma pessoa integrada e total." (Galbreath, citado por George, 1993) Neste novo contexto, a autora năo só define saúde como também envolve a enfermagem, enquanto profissăo voltada para a promoçăo da saúde da pessoa, como uma ciência que presta assistência integral ao individuo, visualizando-o em corpo, mente e espirito e năo apenas como ser portador de patologia ou cliente necessitado de alguma ajuda ao nivel primário. Em seu trabalho Introduction to Nursing, publicado em 1984, ela define o ambiente como "todas as condições, circunstâncias e influências que cercam e afetam o desenvolvimento e o comportamento de pessoas e grupos" (Galbreath, citado por George, 1993). Nesta simples definiçăo, ela descreve o ambiente, numa abordagem holistica, ao mostrar que a interação de estimulos internos do ser humano com estimulos externos, estes últimos, vindos do próprio meio, resultam na formação integralizadora do cosmo, ou melhor, do ambiente.

Em relaçăo às atividades de enfermagem, pouco se evidencia a abordagem holistica neste elemento da teoria, pois, apesar de refletir as açőes a serem desenvolvidas pelo enfermeiro, a autora afirma que este profissional é manipulador dos estímulos que invadem a pessoa, e prepara-a para as mudanças ou enfrentamento dos seus problemas. Dissemos que pouco se evidencia a abordagem holistica neste elemento, por acharmos que não há correlação entre o termo manipulaçăo ou manipular com os pressupostos holisticos. Mas cremos também, que por tratar-se de açōes de enfermagem, estas podem e devem ser realizadas num envolvimento participativo entre cliente e enfermeiro.

\section{TEORIA HOLISTICA DE LEVINE}

Myra E. Levine escreveu uma teoria, cujos principios buscam conservar a energia, a integralidade estrutural, a integralidade pessoal e a integralidade social dos envolvidos no processo de intervençăo da enfermagem. Define individuo como um ser verdadeiramente completo, com necessidades e visto em sua totalidade, afirmando que o enfermeiro deve estar ciente das complexidades dele, num processo interativo e integralizador. A sociedade-ambiente é explicitamente descrita, em seu trabalho, como um espaço onde estăo contidos cliente, enfermeiro, familia e comunidade (Leonard, citado por George, 1993).

Segundo o autor, a saúde é definida por Levine como sendo a manutençăo da unidade integralizadora do individuo. $O$ estado de saúde năo se restringe apenas a varias ou danos fisicos, mas pode ser entendida como qualquer alteraçăo bio-psico-sócio-espiritual que venha a acometer o ser humano. Enfermagem é vista, portanto, como uma ciência humanistica, de natureza holistica, onde o enfermeiro desenvolve o seu pensar e o seu fazer em prol da manutençăo da saúde das pessoas. 
Ainda segundo o mesmo autor pela própria nomenclatura de sua teoria, Levine caracteriza a totalidade da vida humana e o envolvimento do ser humano com o universo. Na teoria de enfermagem de Levine, há um reconhecimento da atividade profissional do enfermeiro, com base nos seus conhecimentos e nas suas habilidades cientificas, onde ele é capaz de assistir ao ser humano em diferentes situaçőes que venham afligir o seu estado de perfeito bem-estar. Em sintese, a teoria Holistica de Levine, descreve que um novo paradigma considerador dos aspectos transculturais reflete as crenças atuais acerca da natureza holistica da humanidade.

\title{
CONSIDERAÇÖES FINAIS
}

Ao elaborarmos o presente estudo, pretendemos divulgar o pensamento holistico como fonte propagadora da integralização do ser humano com o Universo. Com o advir do terceiro milênio, a enfermagem deverá estar preparada para compreender a natureza do ser humano e a sua inserçăo no Cosmo. Os avanços tecnológicos devem ser vistos e utilizados de forma consciente e direcionados para a promoção, proteçăo e recuperaçăo da saúde dos indivíduos.

Ao analisarmos a abordagem holística dentro dos modelos teóricos de enfermagem evidenciamos que a enfermagem desde a época de Florence vem construindo o paradígma holistico, em todas as escolas de pensamento, com vistas a uma abordagem humanística do ser humano em sua indivisivel relaçăo com o meio ambiente. Desta forma reconhecemos que o desenvolvimento desta abordagem holistica à prática profissional do enfermeiro deve dar-se de modo que o ser humano, o ambiente, a saúde e a enfermagem sejam trabalhados numa harmoniosa e totalitária união.

\begin{abstract}
In this bibliographycal analysis, we present the classification of nine theoretical nursing models which frame holistic thinking according to the school of thought of Human Needs, Interaction and Outcome. It further describes the definition of holism, health, client and nursing in the holistic conception, with the objective of portraying holism in the theoretical references of nursing: The Ambiental Theory of Nightingale, the Interpessonal Theory of Peplau, the Philosophical Theory of Hall, The Theory of Basics Principals of Henderson, the Theory of Self Care of Orem, the Prescriptive Theory of Wiedenbach, the Theory of Basic Needs of Horta, the Theory of Adaptation of Roy and the Theory of Holism of Levine.
\end{abstract}

KEYWORDS: Holism, Nursing theories.

RESUMEN: En este estudio bibliográfico analítico presentamos la clasificación de nueve modelos teóricos de Enfermeria que tratan el pensamiento holistico, según las escuelas de pensamiento de las Necesidades Humanas, de la Interacción y de los Resultados. Con base en las definiciones de holismo, salud, cliente/paciente y enfermeria analizamos la perspectiva holistica presentada por los siguientes referenciales teóricos: Teoria Ambientalista de Nightingale, Teoria Interpersonal de Peplau, Teoria Filosófica de Hall, Teoria de los Principios Básicos de Henderson, Teoria del Autocuidado de Orem, Teoria Prescriptiva de Wiedenbach. Teoria de las Necesidades Humanas Básicas de Horta, Teoria de la Adaptación de Roy y Teoria Holistica de Levine.

PALABRAS CLAVE: Holismo, Teorias de enfermería.

\section{REFERÊNCIAS BIBLIOGRÁFICAS}

BELCHER, J. R.; FISH, L.J. B. Hildegard E. Peplau . In : GEORGE, Julia B. et al. Teorias de 
enfermagem: os fundamentos para a prática profissional. Porto Alegre: Artes Médicas, 1993. p. 49-63.

BENNETT, A. M.; FOSTER, P. C. Ernestine Wiedenbach . In : GEORGE, Julia B. et al Teorias de enfermagem: os fundamentos para a prática profissional . Porto Alegre: Artes Médicas, 1993 . p. $151-163$.

FOSTER, P.C.; JANSSENS, W. P. Dorothea E. Orem . In : GEORGE, J. B. et al . Teorias de enfermagem: os fundamentos para a prática profissional. Porto Alegre: Artes Médicas, 1993 . p $90-107$.

FURUKAWA, C.Y.; HOWE, J. K. Virginia Henderson. In: GEORGE, J.B. et al .Teorias de enfermagem: os fundamentos para a prática. Porto Alegre: Artes Médicas , 1993 . p . 64 - 79.

GALBREATH, J. G. Sister Callista Roy. In: GEORGE, J. B . et al. Teorias de enfermagem: os fundamentos para a prática profissional. Porto Alegre: Artes Médicas, 1993. p.206 - 226.

GEORGE, J. B. et al. Teorias de enfermagem: os fundamentos para a prática. Porto Alegre: Artes Médicas, 1993.

HENDERSON, V. Basic Principles of Nursing Care. New York, 1969. p. 3.

HORTA, W. A. Processo de enfermagem. São Paulo: EPU, 1979.

LEONARD, M. K. Myra Estrin Levine. In: GEORGE, J.B. et al. Teorias de enfermagem: os fundamentos para a prática profissional. Porto Alegre: Artes Médicas, 1993. p.164-173.

MELEIS, A. I. Theoretical Nursing: development \& progress. 2. ed. Philidelphia: Library of Congress, 1991. p. 169-180.

NIGHTINGALE, F. Notas sobre enfermagem. Săo Paulo: Cortez, 1989, p. 14-18.

NOGUEIRA, M. J. C. Abordagem holistica: uma proposta para a enfermagem brasileira. In: Anais do XXXVII Congresso Brasileiro de Enfermagem. Recife: ABEn - PE , 1986, p . 508 - 526.

OREM, D. E. Nursing, concepts of practice. 4 ed. St. Louis: Mosby, 1991. 385p.

PEPLAU, H. E. Interpesonal Relations in Nursing: a conceptual frame of references for psychodynamic nursing, Kingdom: MacMillan Education, 1988. p. 3,16.

ROY, C. S., ROBERTS, S. L. Theory construcion in nursing: an adaptation model. $2^{\mathbf{a}}$ ed. Englewood: Cliffs, Prentice-Hall, 1984. P. 43-48.

SARKIS, J. M., SKONER, M. M. An analysis of the concept of holism in nursing literature. Holistic Nurs. Pract. v. 2, n. 1, p. 61-69, 1987.

SILVA, A. L. O saber nightingaliano no cuidado: uma abordagem epistemológica. In: WALDOW, V.R., LOPES, M.J.M., MEYER, D.E. (Ed). Maneiras de cuidar maneiras de ensinar: a enfermagem entre a escola e a prática profissional. Porto Alegre: Artes Médicas, 1995, p. 41-60.

TORRES, G. Florence Nightingale. In: GEORGE, J.B. et al. Teorias de enfermagem: os fundamentos para a prática profissional. Porto Alegre: Artes Médicas, 1993, p . 38 - 48.

WEIL, P. Holistico é e năo é. In: Anais do /l Congresso Holistico Intemacional. Belo Horizonte,1991.

WIEDENBACH, E. Family-Centred Matemity Nursing. New York: Putsnam's Sons, 1958. p. 1, 3. 